\title{
Identifying Coping Profiles and Profile Differences in Role Engagement and Subjective Well-Being
}

\author{
Saija Mauno ${ }^{1, *}$, Marika Rantanen ${ }^{2}$ and Asko Tolvanen ${ }^{2}$ \\ ${ }^{1}$ University of Tampere, University of Jyväskylä, Finland \\ ${ }^{2}$ University of Jyväskylä, Finland
}

\begin{abstract}
Coping strategies are not necessarily mutually exclusive and can be used simultaneously, a fact which has rarely been examined in coping research. We examined what kinds of coping profiles could be found in data concerning Finnish health care and service employees $(n=2756)$. We also studied whether role engagement (family-to-workenrichment, work-to-family-enrichment, emotional energy at work, and work engagement) and subjective well-being (life, parental, and marital satisfaction, and psychological distress) differ between coping profiles. The data were analyzed through latent profile (LPA) and covariance analyses (Ancovas). LPA revealed seven distinct coping profiles: two active groups, one passive group, one low and two high copers' groups and one moderate group. These results indicate that coping strategies are not mutually exclusive and that people might use different strategies simultaneously. The covariance analyses revealed that the most significant differences concerned role engagement: active copers showed higher role engagement (e.g. enrichment, work engagement) than moderate or low copers. The findings imply that the indicators of role engagement deserve more attention in coping research in healthy working adults.
\end{abstract}

Keywords: Coping profiles, coping strategies, latent profile analysis, person-oriented approach, role engagement, well-being.

\section{INTRODUCTION}

Although coping has been actively researched also in the field of work stress since the 1960s, there are still many definitions and theoretical views on coping. "Coping, in sum, is certainly not a unidimensional behavior. It functions at a number of levels and is attained by a plethora of behaviors, cognitions, and perceptions" [1]. The assessment of coping has also been difficult due to inconsistencies in the definition of the construct and to the complexity of the whole phenomenon [2, 3]. Despite these variations, most coping researchers would agree in defining coping as behavioral and cognitive attempts to manage, tolerate, or reduce the stressful demands of a situation [4].

As coping research has progressed coping taxonomies have also been introduced [5]. In these taxonomies, coping has most often been categorized as problem-focused (behavioral coping, e.g. taking direct action), and emotional-focused (cognitive or intrapsychic coping, e.g. positive thinking) even though important limitations have been noticed in such taxonomies [5]. This traditional way of classifying coping strategies into narrow categories is too limited an approach to allow proper understanding of the ultimate nature of coping $[5,6]$. Moreover, narrow taxonomies hardly represent the coping strategies that

*Address correspondence to this author at the University of Tampere and University of Jyväskylä, Department of Psychology, 40014, University of Jyväskylä, Finland; Tel: + 35850 3186770; E-mail: saija.mauno@jyu.fi individuals utilize in real life settings [1, 7]. Coping researchers have therefore recommended investigating coping beyond narrow taxonomies [5, 8, 9].

Accordingly, the starting point in the present study is that coping is a complex construct and that individuals might use different coping strategies simultaneously, so coping strategies are not mutually exclusive. For instance, some individuals might be 'high copers' (using a variety of both problem- and emotion-focused strategies) whereas others might be 'low copers' (not using any strategies very much) [9-11]. Approaching coping from this point of view requires a different methodological approach; that is, a person-oriented analysis instead of a variable-oriented analysis [12]. The basic idea in person-oriented analysis is to cluster or classify individuals into homogeneous sub-groups. In the present study, this meant that we examined how different coping strategies integrated or combined within individuals to form different coping profiles or coping combinations. Specifically, we applied Latent Profile Analysis (LPA) [13] to identify coping profiles and search for homogeneous sub-groups of coping. In addition, in order to externally validate our coping profiles, we examined how well-being and role engagement varied by coping profiles. If differences emerged, this would validate our coping profiles. Moreover, such findings would also have practical value; knowing what sort of coping combinations are most beneficial for well-being and role engagement would help in designing effective coping interventions. 
To our knowledge, this is the first study of coping strategies to focus on a non-clinical working population ( $n=2756$ ) by applying sub-group analysis (LPA) to coping strategies. Earlier studies on coping profiles/typologies have concerned either clinical populations [9, 14] or adolescents [10, 11] but no published study has examined 'healthy' workers from this perspective. However, coping is most likely a critical health-promoting resource also for normal, healthy workers $[15,16]$. Theoretically, our study relied on the cybernetic coping theory $[17,18]$, which we introduce briefly below.

\section{Coping Strategies in the Cybernetic Coping Theory}

Edwards [17] developed an integrative theory of stress, coping, and well-being based on the idea of a negative feedback loop. This theory, known as the cybernetic stress theory, was developed in an occupational context and was therefore an appropriate framework for our study, which focused on 'healthy' working adults. The main idea of this model is that discrepancies between internal needs (desired state) and environmental inputs (perceived state) are crucial in the stressor-strain process. The discrepancies cause stress which, in turn, affects an individual's well-being and activates coping in order to reduce or prevent the negative impact of stress on well-being [4]. Somewhat similar reasoning is apparent in the previously developed person-environment fit theory on work stress [19]. More specifically, Edwards [17, 18] suggests that stress can activate coping directly, in expectation of possible damage to well-being, or indirectly, after well-being has already been damaged. Coping varies from a conscious careful planning, selection, and implementation to an intuitive coping response and no matter what kind of coping is activated its ultimate task is to prevent or reduce the negative effects of stressors on well-being $[1,17,18]$. Coping efforts can be directed toward the determinants of stress or towards the interpretations that the individual puts on the discrepancy.

Specifically, Edwards [17, 18] divided coping behavior into five distinct categories or strategies: changing the situation, accommodation, devaluation, symptom reduction, and avoidance. He argues that these categories are not mutually exclusive and they can be used simultaneously, an idea which offers a good starting point for trying to identify individual-based coping profiles by person-oriented analysis, as we did. Situation changing includes actively solving the problem by modifying the situation and altering the situation to meet one's desires. Accommodation means that a person's own desires are matched to the situation, or that the person changes either their personal expectations or the importance given to the stressful situation. Devaluation can be defined as reducing the significance of the discrepancy by devaluing the importance of discrepancies between one's desires and the situation. The idea of symptom reduction is that one takes direct intra-psychic action to improve one's well-being, which has been damaged or threatened by the stressful event. Avoidance can be seen as directing one's attention away from the stressful situation or discrepancies and in this way reducing the impact of the stressors on one's wellbeing. These five coping strategies, which, in fact, can also be found in other coping models and inventories, e.g., the COPE-scale, [6] can be assessed by the Cybernetic Coping Scale [20], which we used in the present study.

\section{Coping Profiles in Previous Person-Oriented Studies}

As already said, even though the idea that coping strategies are not mutually exclusive and can be used simultaneously is not a new one, only a few previous studies have examined this possibility by trying to establish personal coping profiles (or clusters, typologies). However, none of these earlier studies have sampled the normal working population, as we did. Of these previous studies, two concerned adolescents. Aldridge and Roesch [10] used LPA to examine Hispanic, Asian-Americans, and other minority adolescents. They found three coping profiles: 1) 'low generic', 2) 'active', and 3) 'avoidant' copers. 'Low generic' copers used both active and avoidant coping strategies at a low level. The 'active' group comprised adolescents who used active and approach strategies (planning, instrumental social support, positive reinterpretation) at a high level whereas 'avoidant' copers preferred to use avoidant or passive strategies (such as substance abuse, focusing and venting emotions).

Seiffge-Krenke and Klessinger [11] also identified coping profiles in their longitudinal study of German adolescents. They grouped different coping profiles using a factor analytic approach and found four coping profiles: 'approachers', 'avoiders', 'high generic copers', and 'low generic copers'. 'Approachers' used high levels of approach-oriented and low levels of avoidant coping. 'Avoiders', on the other hand, preferred avoidant strategies and used approach coping only at 
low levels. 'High generic copers' used both avoidant and approach strategies at high levels whereas 'low generic copers' used both coping styles at low levels. Consequently, it seems that 'avoidant', 'active/ approach', and 'low generic' copers were identified in both these studies [10,11], which suggests that these profiles might be generalizable at least to some extent.

We also found two studies which used personoriented analysis in clinical samples when examining coping profiles and their health implications. Walker et al. [14] identified six coping profiles in examining coping with pain by using cluster analysis: 'infrequent', 'self-reliant', 'engaged', 'inconsistent', 'avoidant', and 'dependent'. 'Infrequent' copers rarely used any of the pain-coping strategies. 'Self-reliant' copers used accommodative strategies, for example acceptance, minimizing pain and self-encouragement, at high levels. 'Engaged' copers engaged with both personal and interpersonal resources and reported that they often used problem-solving, distraction, selfencouragement, and seeking social support. 'Inconsistent' copers used strategies which are inconsistent with each other, for example, in personal coping they used high levels of catastrophizing and self-encouragement and in interpersonal coping preferred high levels of both self-isolation and supportseeking. 'Avoidant' copers avoided social contact and kept others from knowing how they felt, and they rarely used self-encouragement or distraction. 'Dependent' copers reported high levels of catastrophizing about pain and in addition some support-seeking.

Later Luyckx et al. [9] identified four coping profiles in their investigation of coping with illness (type I diabetes) using cluster analysis: 'active integrated', 'passive avoidant', 'high generic low integrated', and 'low generic high integrated coping'. The 'active integrated' group used high levels of what they called 'tackling spirit' (for example, having the view that as a result of their own experience they were able to help other people) and diabetes integration (feeling that diabetes is the worst thing that has ever happened, for example) and low levels of passive resignation and avoidance strategies. 'Passive avoidant' copers used high levels of passive resignation and avoidance. In addition, they only rarely used tackling spirit and diabetes integration. 'High generic low integrated' copers frequently used active coping and moderately high levels of passive resignation and avoidance and moderately low levels of diabetes integration. 'Low generic high integrated' copers used high levels of diabetes integration and low levels of all other coping strategies. Only one common coping profile was identified in both these studies: the group of 'passive/avoidant' copers [9, 14].

Even though our method of analysis (LPA) was data driven, signifying that it is difficult to set precise hypotheses, some hypotheses were posed on the basis of coping theories $[4,17,18]$ and the empirical findings presented above on person-oriented coping studies [9, 10, 11, 14]. We expected (Hypothesis 1) to find at least two coping profiles in our data: one group in which active coping strategies (accommodation, symptom reduction, situation changing, and devaluation) are more often used (Group 1) and a second group in which passive (in the present case avoidant) coping strategies are more typical (Group 2). Furthermore, we considered it possible that we would find a group (Hypothesis 2) scoring low in all kinds of coping strategies (Group 3; 'low generic copers') as well as a group scoring high in all coping strategies (Group 4: 'high generic copers'). However, we felt it was equally possible that other kinds of combinations would emerge (various active and passive groups, for instance) especially since we are using a large data set. Previous person-oriented coping studies have used much smaller samples, which also means fewer groups/profiles, because profile computing is based on individual scores, which are likely to show more variation in larger data sets.

\section{Differences in Well-Being and Health According to Coping Profiles/Groups}

The studies that we have already mentioned validated their coping profiles or typologies by examining potential differences in well-being and health shown by each coping profile. This idea is also well in line with coping theory, which argues that different kinds of coping and coping effectiveness, particularly, have implications for well-being and health $[1,4,15$, 16]. In their studies on adolescents' coping, SeiffgeKrenke and Klessinger [11] found that 'approach coping' was related to the lowest symptoms of depression while 'avoidant coping' was associated with the highest ones. Another study of adolescents' coping [10] showed that 'active copers' reported less depression and more stress-related growth than 'low generic copers'. 'Low generic copers', for their part, reported less depression than 'avoidant copers' and less stress-related growth than 'active copers'.

Person-oriented coping studies which have been based on clinical samples have reported rather similar 
findings. Walker et al. [14], for example, found that 'avoidant copers' reported a higher level of depressive symptoms and lower competence (global, school, and social) than the other coping groups. Furthermore, in the group of 'engaged copers', in which problemsolving and self-encouragement and other such strategies were used at high levels, problem-focused coping (for example, perceiving the possibility of doing something to ease the problem) was seen as the most efficient action, and this group reported less depression than the other groups. Luyckx et al. [9], showed that 'active integrated coping' was the most effective profile (showing the lowest depressive symptoms and the highest personal control) and 'passive avoidant' the least effective profile (showing the highest depressive symptoms, for example). In addition, they showed that the 'active integrated' and 'low generic high integrated' groups had the highest self-esteem, while the 'passive avoidant' and 'high generic low integrated' groups had the lowest.

Overall, these results, based on both non-clinical adolescent and clinical adult samples, support earlier well-established findings which show that avoidant or passive (often defined as emotion-focused) coping is mostly maladaptive whereas active or engaged (often defined as problem-focused) coping is mostly adaptive in terms of health and well-being outcomes [15, 16, 21]. However, it is worth remembering that these earlier person-oriented studies on coping approached wellbeing quite narrowly, focusing mainly on depression as a major outcome. Our study examines well-being more broadly covering, for example, satisfaction in the family domain and psychological context-free distress. Moreover, our study also covers role engagement, for example, work engagement and work-family enrichment, which has not been looked at before in person-oriented studies on coping. Despite this earlier neglect it could well be argued that role engagement is a relevant outcome because it describes how well a person is functioning psychologically and socially in different, major life domains $[22,23]$.

On the basis of these previous findings, covering both person- and variable-oriented studies on coping strategies, some tentative hypotheses were posed on well-being and role engagement differences by coping profiles. We predicted that those employees who belong to active/approaching coping groups (there might be more than one 'active group') will show the highest well-being and role engagement whereas those who belong to passive/avoidant groups (again, there might be more than one 'passive group') will show the lowest well-being and role engagement (Hypothesis 3). Moreover, those scoring low in all types of coping ('low copers' in active and passive strategies) are expected to show poorer well-being and role engagement than those who score high ('high copers' in active and passive strategies) in all types of coping (Hypothesis 4). Finally, it should be remembered that our approach to identifying coping profiles was rather explorative: many different coping profiles might emerge, which means that all our hypotheses should be considered tentative.

\section{METHODS}

\section{Procedure and Participants}

The data for this study were collected in October 2009 as part of the research project "Work-family coping strategies as promoters of employee wellbeing". The study was conducted in collaboration with two Finnish trade unions: Tehy and Pam. Members of the former are professional health care workers (including nurses, physiotherapists, social workers, and midwives) and of the latter, service staff (cleaners, waitresses, security staff, and cashiers, for example) employed primarily in the private sector. We used an electronic questionnaire which was distributed by email to each potential participant $(N=7511)$. Random sampling was carried out by representatives of both unions. A total of 2756 individuals participated in the study, yielding a response rate of $36.7 \%$. Even though the response rate was rather low, it can be considered acceptable in occupation- and organization-based research [24]. In the final data we had altogether 1719 health care professionals and 1037 service employees.

$86 \%$ of the respondents were women, which corresponds quite well to the real gender distribution in Finnish labor unions: $93 \%$ of Tehy's and $80 \%$ of Pam's members are women. The respondents were on average $39.4(S D=11.6)$ years old, again a figure which is comparable with the actual situation in labor unions: the average age among Tehy's members is 43 and among Pam's members 40. Thus, in terms of gender and age the respondents corresponded quite well to the target population. Among the respondents the most frequent level of educational achievement was polytechnic or post-secondary, with $58 \%$ of respondents in this group, and $33 \%$ had intermediate vocational or college education. In terms of family situation, $82 \%$ had a spouse or partner and $66 \%$ had children. As for their employment, the participants worked on average 36.8 ( $S D=9.2$ ) hours per week, 
$43 \%$ of the participants worked in shifts, and $85 \%$ of them had a permanent employment contract.

\section{Measures}

Coping strategies were assessed with the Cybernetic Coping Scale [20]. The psychometric properties of the CCS have been validated in previous research $[25,26]$. This 15 -item scale consists of five sub-scales, each of which was measured in our study by three items: accommodation (e.g. "I try to adjust my expectations"), avoidance (e.g. "I try to avoid thinking about the problem"), devaluation (e.g. "I tell myself the problem is unimportant"), symptom reduction (e.g. "I try to relieve my tension somehow"), and change the situation (e.g. "I try to change the situation to get what I want"). Respondents used a five-point scale ranging from 1 (almost never) to 5 (always). Cronbach's alpha for accommodation was $.62(M=3.12, S D=.58)$, for avoidance $.80(M=2.68, S D=.75)$, for devaluation .73 $(M=2.87, S D=.66)$, for symptom reduction $.65(M=$ $3.40, S D=.66)$, and for the situation changing .69 . ( $M$ $=3.10, S D=.66)$.

Psychological distress was assessed with the Occupational Stress Questionnaire [27]. Six items (concerning for example fatigue, sleeping difficulties, irritation, and depression) which describe context-free or general well-being were assessed on a six-point response scale, ranging from 1 (never) to 6 (almost daily). Cronbach's alpha for psychological distress was $.89(M=3.18, S D=1.11)$.

Marital satisfaction was measured by two items drawn from the Kansas Marital Satisfaction Scale drawn up by Schumm et al. [28] (e.g. "How satisfied are you with your marriage?"). The items correlated highly $(r=.79, p<.001)$. Parental satisfaction was assessed by three items from the Kansas Parental Satisfaction Scale devised by James et al. [29] (e.g. "How satisfied are you with yourself as a parent?"). Items were rated on a seven-point response scale, ranging from 1 (very unsatisfied) to 7 (very satisfied). Cronbach's alpha for marital satisfaction was $.97(M=$ $5.79, S D=1.30)$ and for parental satisfaction $.80(M=$ $5.77, S D=.90)$. Life satisfaction was evaluated by one item, "How satisfied are you with your life?". This item was rated on a 7-point response scale, ranging from 1 (very unsatisfied) to 7 (very satisfied). Marital satisfaction correlated with life satisfaction $(r=.53 ; p<$ $.001)$ and with parental satisfaction $(r=.28 ; p<.001)$. Life satisfaction related to parental satisfaction $(r=.43$; $p<.001)$. These correlations between the variables were moderate, so they did not measure the same underlying construct. We therefore analyzed them separately.

Role engagement was operationalized through four constructs: work engagement, work-to-family enrichment, family-to-work enrichment and emotional energy at work. Work engagement refers to a positive, fulfilling, and fairly persistent affective-cognitive, workrelated state of mind characterized by vigor, dedication, and absorption [30]. In the present study, work engagement was assessed with six items drawn from the short form of the Utrecht Work Engagement Scale (UWES-9) [31]. This 6-item scale consists of the subscales of vigor (e.g. "At my work, I feel that I am bursting with energy") and dedication (e.g. "I am proud of the work that I do"). Items were assessed on a seven-point response scale, ranging from 1 (never) to 7 (every day). Cronbach's alpha for work engagement was .93. $(M=5.50, S D=1.25)$.

Overall, work-family enrichment describes the extent to which experiences in one role (work or family) improve the quality of life (for example, performance or affect), in the other role [32]. In the present study it was measured by eight items of the Work-To-Family Enrichment Scale [33]. Four of these items measured work-to-family enrichment (WFE), describing the extent to which one's work life facilitated or enriched one's family life. (e.g. "My involvement in my work makes me satisfied and this helps me be a better family member"). Four items were also used to assess familyto-work enrichment (FWE), illustrating the extent to which one's family life facilitated or enriched one's work life (e.g. "My family life puts me in a good mood and this helps me be a better worker"). Each item was assessed on a seven-point response scale, ranging from 1 (totally disagree) to 7 (totally agree). Cronbach's alpha for WFE was $.83(M=3.88, S D=1.29)$ and for FWE $.85(M=4.87 S D=1.17)$.

Finally, emotional energy at work was evaluated by three items (e.g. "I feel capable of being sympathetic to patients/customers") from the emotional energy sub-scale from the Shirom and Melamed Vigor Scale (SMVM) [34]. Specifically, the sub-scale concerns psychological presence at work in relation to customers and co-workers. We considered this an important aspect of role engagement, especially in the health care and service occupations which we studied. Emotional energy at home was measured by three items similar to those in the emotional energy at work scale except that we replaced "patients/customers" with 
"family members/significant others" (e.g. "I feel capable of being sympathetic to family members/significant others"). Cronbach's alpha for emotional energy at work was $.89(M=5.51, S D=.81)$ and for emotional energy at home $.90(M=5.40, S D=.83)$. The items in these two scales were assessed on a seven-point response scale, ranging from 1 (never) to 7 (always).

Because coping has most relevance in stressful circumstances [1, 2, 4], we also wanted to take into account how much stress was reported by the respondents. Stress was operationalized via the constructs of workload and homeload, describing role overload in two life domains. These variables were also used as covariates (together with labour union, gender, age, education) in examining differences in well-being and role engagement by coping profiles. Specifically, to assess homeload we used three items (e.g." I have lot of responsibilities at home") from the Family Demand Scale developed by Boyar et al. [35]. The items were assessed on a five-point response scale, ranging from 1 (totally disagree) to 5 (totally agree). Workload was measured by a three-item-based sum-scale (e.g. "Do you have too much to do at work?") derived from the QPSNordic questionnaire [36]. The response scale ranged from 1 (almost never) to 5 (very often/always).
Cronbach's alpha for homeload was $.82(M=2.85, S D$ $=.1 .02)$ and for workload $.77(M=3.24, S D=.82)$. Of the participants, $70 \%$ reported workload and $37 \%$ homeload at least occasionally $(M>3.0$, on a scale 1 $5)$, implying that workload was more prevalent than homeload.

Correlations (Pearson) between the studied variables are presented in Table 1. It is noteworthy that correlation coefficients (bolded) are significant at $p$ $<.001$ level. Our sample was so large that very small correlations were also significant $(p<.05)$, although these may have little practical value.

\section{Statistical Analysis}

First, we assessed the factor structure of the Cybernetic coping scale by running Confirmatory Factor Analysis (CFA) using the Mplus 5.0 program [37]. The estimation uses the mean- and varianceweighted least-square method (WLSMV) and theta parameterization. The goodness of the fit of the CFA models was evaluated by the root mean square error of approximation (RMSEA), Tucker Lewis Index (TLI), Comparative Fit Index (CFI), and Weighted Root Mean Square Residual (WRMR). The statistically non-

Table 1: Correlations (Pearson) between the Variables

\begin{tabular}{|c|c|c|c|c|c|c|c|c|c|c|c|c|c|c|c|c|c|c|c|c|}
\hline & 1 & 2 & 3 & 4 & 5 & 6 & 7 & 8 & 9 & 10 & 11 & 12 & 13 & 14 & 15 & 16 & 17 & 18 & 19 & 20 \\
\hline 1. Labor union & 1 & & & & & & & & & & & & & & & & & & & \\
\hline 2. Gender & .26 & 1 & & & & & & & & & & & & & & & & & & \\
\hline 3. Age & -.38 & -.10 & 1 & & & & & & & & & & & & & & & & & \\
\hline 4. Education & -.53 & -.17 & .16 & 1 & & & & & & & & & & & & & & & & \\
\hline 5. Workload & -.15 & -.05 & .16 & .11 & 1 & & & & & & & & & & & & & & & \\
\hline 6. Homeload & .02 & -.04 & -.22 & .00 & .16 & 1 & & & & & & & & & & & & & & \\
\hline 7. Accomodation & .01 & -.06 & .01 & .02 & .04 & .07 & 1 & & & & & & & & & & & & & \\
\hline 8. Avoidance & .11 & -.03 & -.10 & -.08 & -.01 & .10 & .22 & 1 & & & & & & & & & & & & \\
\hline 9. Devaluation & .08 & -.02 & .00 & -.08 & -.06 & -.02 & .32 & .54 & 1 & & & & & & & & & & & \\
\hline 10. Symptom reduction & -.02 & -.11 & -.08 & .08 & .04 & .06 & .32 & .32 & .25 & 1 & & & & & & & & & & \\
\hline 11. Situation changing & -.00 & -.02 & -.06 & .08 & .08 & .07 & .33 & .05 & .11 & .33 & 1 & & & & & & & & & \\
\hline 12. Distress & .13 & -.00 & -.16 & -.07 & .34 & .34 & .06 & .13 & -.04 & .11 & .07 & 1 & & & & & & & & \\
\hline 13. Life satisfaction & -.14 & -.08 & .12 & .08 & -.12 & -.24 & -.02 & -.08 & .06 & .02 & -.01 & -.48 & 1 & & & & & & & \\
\hline 14. Marital satisfaction & -.01 & .01 & -.08 & -.01 & -.07 & -.21 & -.00 & -.06 & .01 & .02 & -.02 & -.25 & .53 & 1 & & & & & & \\
\hline 15. Parental satisfaction & -.07 & -.01 & .08 & .01 & -.12 & -.22 & -.04 & -.08 & .02 & -.01 & -.03 & -.33 & .43 & .28 & 1 & & & & & \\
\hline 16. FWE & -.08 & -.07 & -.03 & .09 & -.03 & -.03 & .09 & -.04 & .02 & .09 & .11 & -.18 & .34 & .38 & .21 & 1 & & & & \\
\hline 17. WFE & -.22 & -.06 & .07 & .14 & -.10 & .01 & .10 & -.06 & .02 & -.00 & .07 & -.28 & .18 & .04 & .12 & .37 & 1 & & & \\
\hline 18. Work engagement & -.20 & -.11 & .19 & .12 & -.09 & -.11 & .08 & -.12 & .01 & -.02 & .06 & -.40 & .32 & .09 & .20 & .21 & .45 & 1 & & \\
\hline 19. Energy at work & -.17 & -.18 & .13 & .11 & .00 & -.03 & .08 & -.11 & .01 & .04 & .07 & -.19 & .21 & .08 & .20 & .20 & .21 & .40 & 1 & \\
\hline 20. Energy at home & -.08 & -.11 & .03 & .05 & -.11 & -.18 & .04 & -.10 & .03 & .04 & .04 & -.34 & .44 & .37 & .39 & .32 & .13 & .27 & .41 & 1 \\
\hline
\end{tabular}

Note. For bolded correlation coefficients $p \leq .001$. 
significant $X^{2}$-value, the value of RMSEA smaller than 0.06 , the values of TLI and CFI greater than 0.95 and WRMR lower than .90 show a good fit of the model [37]. For the next step in analysis the factor scores were saved in the file.

After running CFA we continued our analyses with factor scores by identifying coping profiles via mixture modelling, and specifically with Latent Profile Analysis (LPA). LPA is a sub-type of Latent Class Analysis (LCA) but they differ in one respect: LCA is often based on categorical variables whereas LPA is a better alternative for continuous variables, which we used in assessing coping (coping strategies were measured on a 1-5 response scale). Specifically, LPA assumes that the studied constructs, coping strategies in the present case, are independent of one another within their class and consists of latent profiles [37]. LPA uses the categorical latent class variable to group or classify individuals into categories, consisting of individuals who are homogeneous to each other in the same category and heterogeneous between categories. LPA is a useful method when seeking to identify homogeneous sub-groups in a dataset because it also detects small differences between the profiles (or latent groups) and allows statistical testing of the best profile solution (for fit indices, see the following paragraph), which is a clear advantage compared to some of the more traditional group-based methods, for instance, cluster analysis. Furthermore, in applying LPA it is possible to construct measurement error free latent factors, which then can be used as basis for classifying individuals $[13,37,38]$. In the present study, LPA was performed with Mplus 5.0 [37].

There are several statistical and other criteria that can be used to decide the number of latent classes/groups. Here, we used Akaike's Information Criterion (AIC), the Bayesian Information Criterion $(B I C)$, the sample size-adjusted Bayesian Information Criterion (aBIC), the Bootstrap Likelihood Ratio Test (BLRT), the Vuong-Lo-Mendel-Rubin test (VLMR), and the adjusted Vuong-Lo-Mendel-Rubin test (LMR). The $\mathrm{AIC}, \mathrm{BIC}$, and $\mathrm{aBIC}$ are relative fit indices: the smaller their values, the better the class solution [37]. Some other fit indices, such as the BLRT, VLMR and LMR tests, compare solutions with different numbers of latent classes: a low $p$-value $(p<.05)$ indicates that the null hypothesized model with $k-1$ classes must be rejected in favor of the alternative hypothesized model with $k$ classes [37]. Furthermore, in LCA (also in LPA), the statistical quality of the group classification (i.e., how well the model classifies individuals into sub- groups) can be evaluated via Average Latent Class Posterior Probabilities (AvePP) [37]. The values of AvePP vary between 0 and 1: the higher the values, the more distinguishable the latent groups are from each other. Usually, AvePP values greater than .70 is used as a rule of thumb to indicate that the found solution can be interpretable using the mean trajectories [38]. Also, entropy values are often used to assess the goodness of group/class solutions and range from 0 to 1 , where high values $(>0.90)$ indicate that the latent classes are highly discriminative [38]. The criteria that are important in deciding the number of latent classes are the usefulness and clarity of the latent classes. Clarity is evaluated primarily with AvePP and entropy values, while the quality of the classification can be evaluated in terms of the separation of the latent classes. Both AvePP and entropy values were used in this study to evaluate clarity of group/profile solution.

Our second aim, after identifying the coping profile groups, was to investigate whether the coping profile groups differ in well-being and role engagement. To examine this, individuals were placed in the class whose posterior probability was highest and saved as an SPSS data file. SPSS version 16 was used to perform the covariance analysis (ANCOVA), which tests whether factors have an effect on the outcome variable after removing the variance which covariates (gender, age, education, labor union, workload and homeload) account for. Bronferoni pairwise comparison was used to determine which groups differed from each other if the general F-test showed significant values.

\section{RESULTS}

\section{Results of CFA for Coping Strategies}

CFA revealed five distinct coping strategies (accommodation, avoidance, revaluation, symptom reduction, and changing situation), as was hypothesized on the basis of initial scale structure suggested by Edwards and Baglioni [20]. The final factor model, after freeing some of the covariances between residuals, fitted the data sufficiently $\left(\chi^{2}(42)=577.93, p<.001, \mathrm{CFI}=.95, \mathrm{TLI}=.97, \mathrm{RMSEA}\right.$ $=.07, \mathrm{WRMR}=1.82)$. Detailed psychometrical information (e.g. factor loadings, factor intercorrelations, residual correlations between the observed variables) are provided in Figure 1 and means for normalized factor z-scores according to the coping profiles can be found in Appendix 1. Even though the residual correlations were very small (see 
Figure 1), the large sample size $(N=2537)$ in the model decreased the fit of the model to a considerable extent. The standardized factor loadings (ranging between .46 and .85 ) were all statistically significant. The factors correlated with each other but not very highly: the highest correlation $(r=.53)$ was between situation changing and symptom reduction and the lowest $(r=.03)$ between avoidance and situation changing.

Thus, we ended up with a five-factor model, which was identical to the initial model tested by Edwards and Baglioni $[20,25,26]$, with the factors accommodation, devaluation, symptom reduction, situation changing, and avoidance. The factor scores were saved and subsequent LPA was based on these factor scores.

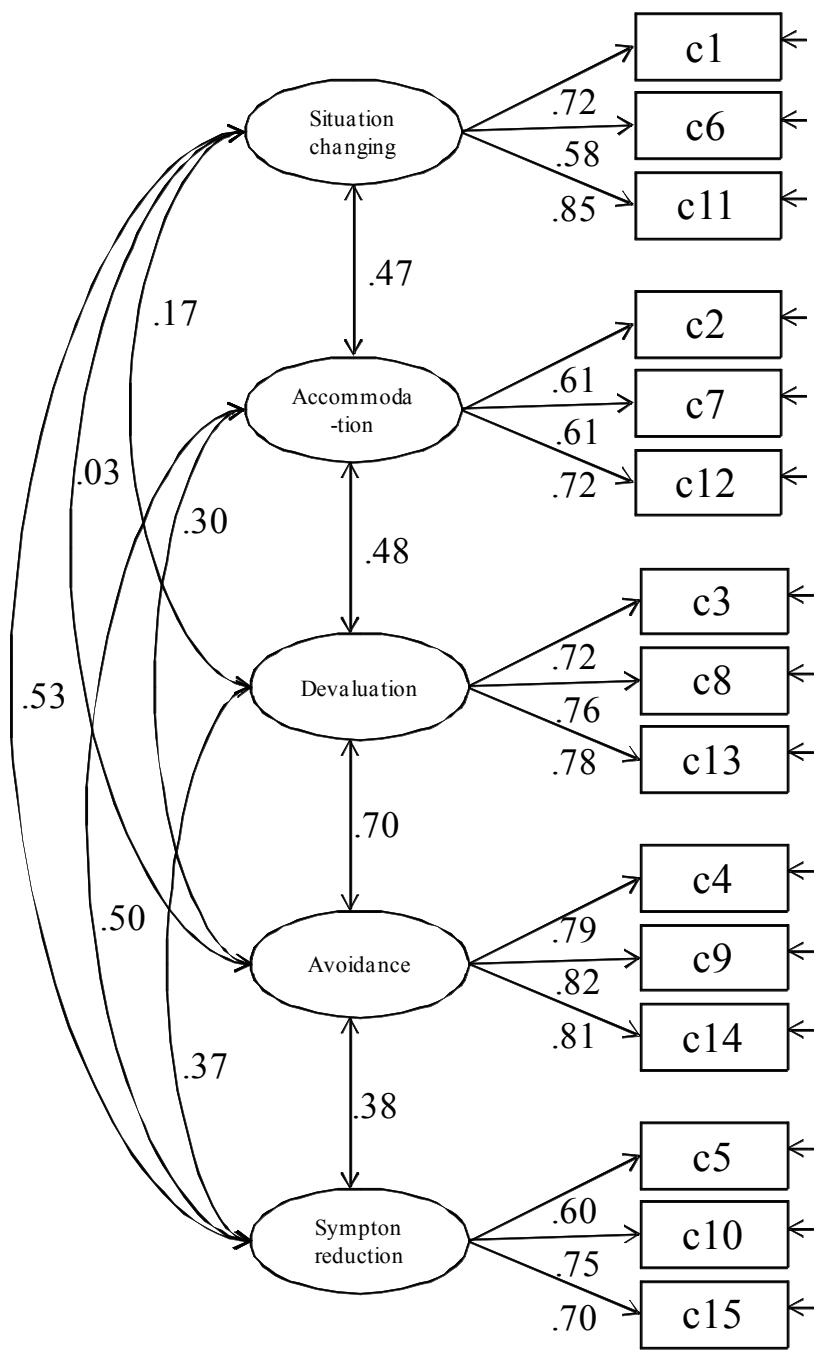

Figure 1: The final factor model of coping scales.

\section{Coping Profiles Found in the Data}

As the model $\mathrm{AIC}, \mathrm{BIC}$ and $\mathrm{aBIC}$ fit indices for the 1 - 8-class solutions presented in Table 2 show, they decreased from 1 to 8 , which suggested that the 8class solution was the best fitting model. Also, the BLRT test suggested an 8-class solution. The VLMR and LMR tests, on the other hand, pointed to another conclusion: these tests indicated that the null hypothesized model with the 7-class solution cannot be rejected at $p<.05$ level when compared to the alternative hypothesized model of the 8-class solution, suggesting that the 7-class solution was the best fitting model. In addition, these 7 classes had the following AvePP values: Class I 0.89 , Class II 0.84 , Class III 0.95 , Class IV 0.84, Class V 0.85, Class VI 0.91, and Class VII 1.0. These values are clearly above 0.70 , which is used as the criterion for the clarity of the group solution in AvePP [38]. The analysis was also continued to compute fit indices for the 9-17-class solutions. However, according to the entropy values, when more than 8 class solutions were fitted, the clarity of the class differences decreased (values available from the authors upon request). Consequently, according to these fit indices and a careful contentrelated interpretation, we ended up with the 7-class solution, which was used in the subsequent analysis.

The profiles (henceforth for clarity labeled groups) and their sizes are presented in Figure 2. In the figure, being above the median means that this coping strategy is used more than average and being below means that it is used less than average. Group 1 contained employees who used each of the five coping strategies at a moderate level (labeled 'moderate copers'). This was also the largest group, consisting of nearly half of the participants. Group 2 (labeled 'low copers') and Group 3 (labeled 'passive copers') consisted of individuals who used every coping strategy less than average, Group 3 even more rarely than Group 2. Group 4 consisted of employees who used changing the situation and symptom reduction more often than average (and devaluation and avoidance less than average). We labeled this group 'blurred copers' because changing situation as a coping strategy best captures the essence of problemfocused coping whereas symptom reduction describes the essence of emotion-focused coping. Group 5 consisted of employees who used more than average situation changing, accommodation and symptom reduction. They were labeled 'active copers' (Group 5) because avoidance and devaluation were not often used in this group. Groups 6 (labeled 'high copers') and 7 (labeled 'the highest copers') contained employees who used all coping strategies more than average, Group 7 even more than Group 6. 
Table 2: Model Fit Indices for the 1-, 2-, 3-, 4-, 5-, 6-, 7-, and 8-Class Solutions

\begin{tabular}{|ccccccccc|}
\hline $\begin{array}{c}\text { Fit } \\
\text { index }\end{array}$ & AIC & BIC & Adj. BIC & VLMR & LMR & BLRT & $\begin{array}{c}\text { Log-likelihood } \\
\text { (df) }\end{array}$ \\
\hline \hline 1-class & 36018.971 & 36077.358 & 36045.585 & - & - & - & $-17999.485(10)$ \\
2-class & 33621.219 & 33714.638 & 33663.802 & .000 & .0000 & .0000 & $-16794.609(16)$ & .710 \\
3-class & 32385.127 & 32513.580 & 32443.680 & .0053 & .0058 & .0000 & $-16170.564(22)$ & .814 \\
4-class & 31737.364 & 31900.849 & 31811.885 & .0434 & .0456 & .0000 & $-15840.682(28)$ & .798 \\
5-class & 31207.674 & 31406.191 & 31298.164 & .1470 & .1505 & .0000 & $-15569.837(34)$ \\
6-class & 30818.096 & 31051.645 & 30924.554 & .0089 & .0096 & .0000 & $-15369.048(40)$ \\
7-class* & 30426.846 & 30695.428 & 30549.274 & .0000 & .0000 & .0000 & $-15167.426(46)$ \\
8-class & 30167.962 & 30471.576 & 30306.359 & .2210 & .2261 & .0000 & $-15031.981(52)$ \\
\hline
\end{tabular}

AIC = Akaike Information Criterion; BIC = Bayesian Information Criterion; Adj. BIC = Sample size-adjusted Bayesian Information Criterion; VLMR = Vuong-LoMendall-Rubin likelihood difference test; LMR = Lo-Mendell Rubin; BLRT = Bootstrap likelihood ratio test.

*Indicates the selected best profile solution.

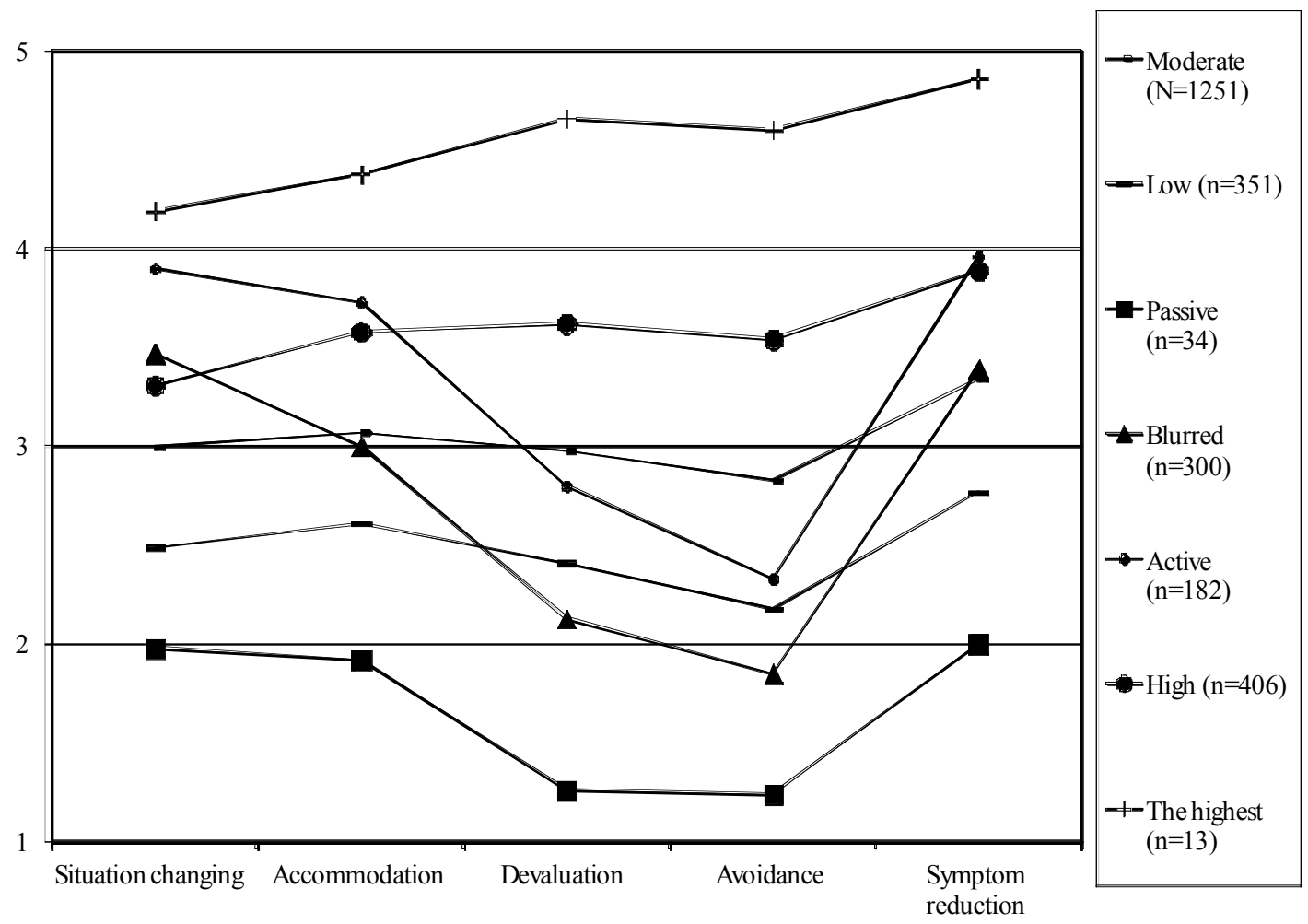

Figure 2: The level of coping (5 strategies) by seven coping profiles.

Table 3 summarizes the differences between coping groups in terms of certain background factors. There were more health care workers than expected amongst the 'blurred' and 'moderate' copers. 'High copers', in contrast, were represented more often than expected among service employees. There were not many gender differences between the coping groups but amongst the 'low copers' there were more men than expected. Nor were there many age differences between the coping groups. Only the 'high copers' group contained a higher than expected number of individuals who were 28 years or younger. More differences were found in education. The 'blurred copers' group contained more individuals than expected with a higher level of education: more employees in this group had polytechnic, Master's or doctoral degrees than in the group of 'passive copers'. Also the group of 'active copers' contained more individuals with a Master's degree or a PhD. The 'high copers' group had fewer Master's or doctoral degrees 
Table 3: The Background Characteristics for Coping Profiles (\% or M, SD)

\begin{tabular}{|c|c|c|c|c|c|c|c|}
\hline Characteristics & $\begin{array}{l}\text { Moderate I } \\
(n=1251)\end{array}$ & $\begin{array}{c}\text { Low II } \\
(\mathrm{n}=351)\end{array}$ & $\begin{array}{c}\text { Passive III } \\
(n=34)\end{array}$ & $\begin{array}{c}\text { Blurred IV } \\
(n=300)\end{array}$ & $\begin{array}{l}\text { Active V } \\
(n=182)\end{array}$ & $\begin{array}{l}\text { High VI } \\
(n=406)\end{array}$ & $\begin{array}{l}\text { Highest VI } \\
\quad(n=13)\end{array}$ \\
\hline \multicolumn{8}{|l|}{ Labor union } \\
\hline Health care & $62^{*}$ & 58 & 62 & $66^{*}$ & 62 & $49^{* * *}$ & 39 \\
\hline Service & $38^{*}$ & 42 & 38 & $34^{*}$ & 38 & $51^{* * *}$ & 61 \\
\hline \multicolumn{8}{|l|}{ Gender } \\
\hline Woman & 87 & $80^{* *}$ & 82 & 84 & 89 & 87 & 92 \\
\hline Men & 13 & $20^{* *}$ & 12 & 16 & 11 & 13 & 8 \\
\hline \multicolumn{8}{|l|}{ Age } \\
\hline$<28$ & 22 & 22 & 15 & 19 & 25 & $29^{* *}$ & 15 \\
\hline $29-45$ & 43 & 44 & 49 & 42 & 48 & 38 & 39 \\
\hline $46-55$ & 26 & 26 & 21 & 28 & 21 & 23 & 46 \\
\hline $56>$ & 9 & 8 & 15 & 11 & 7 & 10 & 0 \\
\hline \multicolumn{8}{|l|}{ Education } \\
\hline Elementary & 5 & $11^{* * *}$ & 12 & 4 & 3 & 7 & 8 \\
\hline Secondary & 35 & 33 & 21 & $26^{* *}$ & 32 & 36 & 31 \\
\hline Polytechnic & 57 & 53 & 56 & $65^{\star *}$ & 58 & 55 & 54 \\
\hline MA degree > & 3 & 3 & $12^{* *}$ & $6^{* *}$ & $7^{* *}$ & $1^{*}$ & 8 \\
\hline \multicolumn{8}{|l|}{$\mathrm{M} / \mathrm{SD}$} \\
\hline Workload $^{1}$ & $3.20 / 0.78$ & $3.19 / 0.80$ & $3.27 / 1.10$ & $3.35 / 0.84$ & $3.38 / 0.84$ & $3.26 / 0.90$ & $3.28 / 0.99$ \\
\hline Homeload $^{2}$ & $2.55 / 0.83$ & $2.40 / 0.88$ & $2.44 / 0.96$ & $2.53 / 0.85$ & $2.69 / 0.93$ & $2.63 / 0.93$ & $2.78 / 1.44$ \\
\hline
\end{tabular}

${ }^{1}$ Difference between coping profiles significant $(F=2.54, p<.050)$. Post hoc tests for paired groups non-significant.

${ }^{2}$ Difference between coping profiles significant $(F=2.90, p<.010)$. Post hoc tests for paired groups non-significant.

Adjusted residual score for a given subgroup ${ }^{*}<-1.96$ or $>1.96, p<.05$; ${ }^{* *}<-2.58$ or $>2.58, p<.01$; ${ }^{* * *}<-3.29$ or $>3.29, p<.001$.

than expected. A lower level of education was found more often than expected amongst 'low copers'. We also examined whether the coping groups differed in perceived workload and homeload. The ANOVAs showed differences for workload $(F(2527)=2.54, p<$ $.050)$ and homeload $(F(2160)=2.90, p<.010)$. However, the post hoc tests (Bronferoni) showed nonsignificant differences, implying that the groups did not differ from each other in paired comparisons. The overall tendency was that 'active' and 'highest' copers reported the highest homeload, whereas 'blurred' and 'active' copers reported the highest workload (for $M$ and SD, see Table 3).

\section{Differences in Well-Being and Role Engagement According to Coping Groups}

The results of mean comparison analyses for wellbeing and role engagement variables according to coping groups are presented in Table 4. In these analyses, we omitted the 'highest copers' (Group 7) because it was too small for these comparative purposes (for the family-related dependent variables there were only 4 respondents). For the indicators of well-being, we found that 'high' (Group 6) and 'low' (Group 2) copers reported higher marital satisfaction than 'moderate copers' (Group 1). However, it is noteworthy that marital satisfaction was highest among 'passive copers' (Group 3) but this effect did not reach significance, apparently because the size of this group was much smaller $(n=34)$ than the other groups. In addition, there were no significant differences in psychological distress, life or parental satisfaction between the coping groups. For the indicators of role engagement, we found that 'active copers' (Group 5) reported higher FWE, WFE, work engagement, and emotional energy at work and home than 'moderate' (Group 1; except for WFE) or 'low' copers (Group 2, for FWE, WFE). Again, the means reveal that 'passive' copers (Group 3), in fact, showed the highest energy level at work and home but the group did not differ significantly from other groups in the post hoc tests, obviously because of its small size relative to the other groups.

In sum, it was shown that active general coping (often using symptom reduction, accommodation, and situation changing), in particular, was more beneficial than low or moderate coping to role engagement. However, differences between coping groups in wellbeing were more modest than we expected. It should be borne in mind that in these analyses we controlled 
Table 4: Differences in Well-Being and Role Engagement by Six Coping Profiles

\begin{tabular}{|c|c|c|c|c|c|c|c|c|c|c|}
\hline \multirow[t]{2}{*}{ Variables } & Moderate & $\begin{array}{c}\text { Low } \\
\text { II }\end{array}$ & $\begin{array}{c}\text { Passive } \\
\text { III }\end{array}$ & $\begin{array}{l}\text { Blurred } \\
\text { IV }\end{array}$ & Active $\mathrm{V}$ & High VI & $\begin{array}{c}F, \\
\text { p-values }\end{array}$ & $\mathbf{R}^{2}$ & $\begin{array}{c}\text { Paired } \\
\text { comparison }\end{array}$ & $\begin{array}{l}\text { Significant } \\
\text { covariates }^{1}\end{array}$ \\
\hline & M/SD & M/SD & M/SD & M/SD & M/SD & M/SD & & & & \\
\hline \multicolumn{11}{|c|}{ Well-being indicators } \\
\hline Distress & $3.13 / 1.03$ & $2.96 / 1.10$ & $2.83 / 1.42$ & $3.22 / 1.21$ & $3.28 / 1.16$ & $3.28 / 1.14$ & $1.93 \mathrm{~ns}$ & .25 & & $1,3,5,6$ \\
\hline $\begin{array}{c}\text { Life } \\
\text { satisfaction }\end{array}$ & $5.75 / 1.04$ & $5.90 / 1.07$ & $5.82 / 1.36$ & $5.77 / 1.16$ & $5.76 / 1.11$ & $5.86 / 1.01$ & $1.71 \mathrm{~ns}$ & .08 & & $1,5,6$ \\
\hline $\begin{array}{c}\text { Parental } \\
\text { satisfaction }\end{array}$ & $5.75 / 0.87$ & $5.85 / 0.89$ & $5.75 / 1.10$ & $5.76 / 0.86$ & $5.76 / 0.96$ & $5.71 / 0.92$ & $0.46 \mathrm{~ns}$ & .06 & & $1,5,6$ \\
\hline $\begin{array}{c}\text { Marital } \\
\text { satisfaction }\end{array}$ & $5.70 / 1.33$ & $5.93 / 1.16$ & $6.20 / 1.11$ & $5.78 / 1.35$ & $5.80 / 1.39$ & $5.92 / 1.25$ & $2.45^{\star}$ & .07 & II, VI > I & $1,3,6$ \\
\hline \multicolumn{11}{|c|}{ Role engagement indicators } \\
\hline $\begin{array}{c}\text { FW- } \\
\text { enrichment }\end{array}$ & $4.81 / 1.11$ & $4.85 / 1.14$ & $4.86 / 1.40$ & $5.00 / 1.16$ & $5.24 / 1.21$ & $5.00 / 1.19$ & $4.95^{* * *}$ & .02 & V > I, II & $1,2,3,4,6$ \\
\hline $\begin{array}{c}\text { WF- } \\
\text { enrichment }\end{array}$ & $3.85 / 1.26$ & $3.78 / 1.28$ & $3.90 / 1.22$ & $3.95 / 1.28$ & $4.11 / 1.30$ & $3.91 / 1.34$ & $2.27^{*}$ & .07 & $V>$ II & 1,5 \\
\hline $\begin{array}{c}\text { Work } \\
\text { engagement }\end{array}$ & $5.49 / 1.23$ & $5.61 / 1.25$ & $5.47 / 1.45$ & $5.63 / 1.30$ & $5.74 / 1.18$ & $5.51 / 1.25$ & $2.36^{*}$ & .08 & $V>I$ & $1,2,3,4,5,6$ \\
\hline $\begin{array}{c}\text { Energy at } \\
\text { work }\end{array}$ & $5.48 / 0.79$ & $5.59 / 0.72$ & $5.86 / 0.70$ & $5.59 / 0.74$ & $5.77 / 0.72$ & $5.57 / 0.86$ & $6.37^{* * *}$ & .05 & $V>I$ & $1,2,3,5$ \\
\hline $\begin{array}{l}\text { Energy at } \\
\text { home }\end{array}$ & $5.37 / 0.78$ & $5.53 / 0.78$ & $5.79 / 0.76$ & $5.44 / 0.74$ & $5.58 / 0.80$ & $5.49 / 0.82$ & $5.47^{\star \star *}$ & .06 & $V>I$ & $1,2,3,5,6$ \\
\hline
\end{tabular}

Note. Models adjusted for $1=$ Labor union, $2=$ gender, $3=$ age, $4=$ education, $5=$ workload and $6=$ homeload

${ }^{1}$ Significant covariates in each model ( $p<.05$ or lower) are marked by these numbers.

${ }^{*} p<.05,{ }^{* *} p<.01,{ }^{* * *} p<.001$

for several factors, for example perceived workload and homeload, which often showed robust main effects on impaired well-being and role disengagement (see the last column in Table 4). Even after adjusting for various covariates, the 'active copers' showed higher role engagement than some of the other groups.

\section{DISCUSSION}

The main goal of our study was to identify what kinds of coping profiles our data, drawn from Finnish non-clinical health care and service employees, consisted of. In addition, we examined whether wellbeing (life, parental, and marital satisfaction, and psychological distress) and role engagement (family-towork-enrichment, work-to-family-enrichment, emotional energy at work, and work engagement) differ between coping profiles, differences which, if found, would support their external validity. To the best of our knowledge, this is the first study which has identified coping profiles by adopting a sub-group analytical approach conducted in a non-clinical working population. We also used a broad range of well-being and role engagement indicators, which we regard as an additional strength since both characterize adaptive adult behavior in different life domains and are therefore relevant to coping.

\section{Seven Coping Profiles were Found in the Data}

On the basis of coping theories [4, 17, 18], we expected (Hypothesis 1) to find at least two coping profiles in our data, that is, active (or approaching) and passive (or avoidant). However, we also allowed for the possibility that several coping profiles would emerge, for example, many active or passive groups, because we used quite a large sample $(n=2756)$. Previous typological studies on coping $[10,11]$ have used smaller data sets, which also mean fewer coping profiles because lower variation often characterizes smaller samples.

LPA revealed seven distinct coping profiles: 'moderate' $(n=1251)$, 'low' $(n=351)$, 'passive' $(n=$ $34)$, 'blurred' $(n=300)$, 'active' $(n=351)$, 'high' $(n=$ $406)$, and the 'highest' $(n=13)$ copers. In this respect the study provided only partial support for $\mathrm{H} 1$, which suggested two main coping profiles (that is, active as opposed to passive). Instead, we found two 'active' 
coping groups: Active (situation changing, accommodation, and symptom reduction) coping was used at high levels among blurred copers and in the active coping group, to which $19 \%$ of participants belonged. This finding was in line with previous typological studies on coping, in which this type of active coping group has also been found [9-11]. The fact that we found two active groups might also reflect the fact that we studied a 'healthy' working population in which employees might well have several adjustive coping strategies. In clinical samples the results would have been different $[9,14]$.

However, passive coping (described by avoidant strategy in the cybernetic coping model) was not used as the main coping strategy in any of the coping groups we found, a finding which was contrary both to our hypothesis $(\mathrm{H} 1)$ and to previous studies [9-11, 14], in which 'avoiders' have formed their own coping group. Among our respondents the avoidance strategy was used at a relatively high level by several groups but not as the main coping strategy in any of the groups. For example, in the 'highest' and 'high' copers groups avoidance was used above the median but only in combination with other more adaptive coping strategies (see Figure 2). This is a promising finding because high avoidance has been shown to be a less adaptive coping strategy which results in many negative outcomes $[16,21]$. It could be that in 'healthy' adult populations avoidance is not needed because other more adaptive coping strategies can easily be activated. However, it should be noted that discrepancies between our study and previous (personoriented) studies on coping might reflect not only sample differences but also measure differences. Earlier studies have used different coping inventories than we used, and coping inventories often measure different sub-categories of coping [5].

Secondly, we hypothesized (Hypothesis 2) that we would find coping groups which would have either low or high levels in relation to all the studied coping strategies, forming groups of 'low' and 'high' generic copers. In line with this hypothesis and previous studies [9-11], our results indeed identified four distinct coping profiles which were either low or high in all five coping strategies studied. Two of these profiles coped at high levels and two at low levels. 'High' copers and the 'highest' copers used all coping strategies above their median. These groups consisted of $16.5 \%$ of participants. About the same proportion of respondents $(15.1 \%)$ was identified as 'passive' copers (low in all coping strategies, especially in devaluation and avoidance) and 'low' copers (all coping strategies were used less than average). These results might reflect individuals' general personal styles of managing stressful situations, their lifestyle or their response style. Some individuals may in a general way have an active or a passive lifestyle as well as differences in the intensity with which they experience things or feel different emotions, for example, due to differences in temperament [39]. This might explain the kind of coping strategies that are activated in stressful situations and at what level (intense or less intense coping).

Finally, we also found a very large moderate (49.3\%) coping group, in which individuals used all coping strategies at a moderate level. In other typological studies on coping this kind of moderate group has not been identified [9-11, 14]. Again this may relate to sample and measure differences; we studied a non-clinical working population, which might well consist of 'moderate' or 'neutral' copers, and we also used a different coping inventory (CCS) than has been used before. Furthermore, the statistical analysis (LPA) used here might produce different group/profile solutions than other more traditional person-oriented methods of analysis, e.g. cluster analysis.

Naturally it has to be pointed out that people face very different stressful events in terms of number or severity, which will naturally be reflected in the coping strategies they use. It is also clear that people appraise situations individually, as is emphasized in the transactional stress model [2, 4]. A future challenge for person-oriented studies on coping is to examine coping profiles or typologies and take into account the type and severity of the stressful situation (applying a situation-specific coping model). One interesting question, for example, is whether certain coping combinations are more typical in certain stressful situations. Here, we also tested whether the coping groups differed in perceived workload and homeload, as these were considered the two most typical role stressors in adults' lives. However, rigorous statistical testing (post hoc tests) found no significant differences between the coping groups in workload or homeload. Naturally, other types of stressors may exist in which such differences would emerge, indicating that more attention should be paid to the nature of stressors in coping studies. Because we took as our starting point a dispositional model of coping, that is, the idea that people tend to use similar coping combinations across situations, an examination of different stressors was beyond the scope of this study. 


\section{Differences in Well-Being and Role Engagement by Coping Profiles}

Besides identifying coping profiles we also
examined differences in well-being and role
engagement according to these profiles. If differences emerge, this would externally validate our coping profiles. Specifically, we hypothesized (Hypothesis 3), in line with previous studies, that those individuals who use active/approach coping strategies (situation changing, accommodation, devaluation, and symptom reduction) would experience the highest well-being and role engagement whereas those who use passive/avoidant strategies (avoidance) would report the lowest well-being and role engagement [6, 14-16, 40]. In addition, we hypothesized (Hypothesis 4) that those who use high levels of all types of coping strategies ('high copers') would report better well-being and role engagement than those who use low levels of coping strategies ('low copers'). A good package of coping strategies could be an important personal resource $[1,4,15]$, and thus relate to higher well-being and psychosocial functioning in different life roles, which was described as role engagement in our study $[22,23]$.

Overall, we found more differences between the groups in the indicators of role engagement than those of well-being, and thus only partial support for our hypotheses (H3, H4). Specifically, 'active copers' (those who used situation changing, accommodation and symptom reduction more than on average and avoidance and devaluation less than on average) reported higher role engagement (WFE, FWE, work engagement and emotional energy at work and home) than the 'moderate' or 'low' copers (for enrichment only), a finding which was also consistent with $\mathrm{H} 3$ and H4. Thus, active coping was related to higher role engagement as we had expected. Furthermore, both the 'high' and 'low' copers showed higher marital satisfaction than the 'moderate' copers, which was a mixed finding (low copers were expected to show poor and high copers good well-being). In fact, the highest marital satisfaction, and also energy level at work and home, was reported by the 'passive copers' (used all the coping strategies less than on average and even less than 'low' copers) but this group did not differ from the other groups when subjected to rigorous statistical comparison (post hoc test), possibly because the size of this group was small $(n=34)$ compared to the other groups. To sum up, the results on differences in wellbeing and role engagement were rather mixed; the only consistent finding was that the 'active copers' often fared better than some other groups. However, this finding can be considered relatively robust as we adjusted several covariates (e.g. perceived workload and homeload) before entering the coping groups into the analyses.

A few earlier person-oriented coping studies have also reported that active coping is beneficial to wellbeing, for example, in terms of lower depression [10, 11]. Nevertheless, the indicators of role engagement have rarely been studied in association with coping strategies, and to our best knowledge, this was the first person-oriented study on coping to focus on role engagement alongside well-being. In this respect, our findings are promising: future coping studies should also examine role engagement as a correlate (or outcome) of coping behaviors, since in a healthy working population coping might have its greatest relevance for an individual's involvement and psychosocial functioning in both the work and family roles.

We see at least three reasons why the well-being differences between the coping groups were so modest (detected only for marital satisfaction). First, as just mentioned, we studied a healthy working population, a sample in which coping might matter less for well-being than role engagement. In clinical samples, the results might be different. Second, it is very likely that the relationship between coping strategies and well-being is mediated by other factors, as suggested by the transactional stress theory [4]. An examination of such mediating processes was beyond the scope of this study, and also given the cross-sectional nature of our data, impossible. One interesting idea for future studies would be to clarify whether role engagement mediates the relationships between coping strategies and wellbeing. Third, it is also possible that other resource factors, for example social support or certain personality factors (e.g. resilience, self-efficacy), have a greater effect on well-being than coping strategies per se. Unfortunately, social support is not explicitly measured in the Cybernetic Coping Scale which we used. Consequently, future coping studies should cover a broad variety of coping resources (coping strategies, support or/and personality resources) to be better able to predict different outcomes. After all, coping strategies are only one type of coping resources, and other types of resources or their combinations might matter more for certain outcomes. 


\section{Limitations and Implications}

This study has a few noteworthy limitations. The first is that the design was cross-sectional, making it impossible to examine the causal directions of the relationships. The second limitation is that our measures were based on self-reported data and are thus sensitive to common method variance bias. A multi-methodological approach, that is, combining selfreport and objective data, would be a good choice, although personal coping is naturally difficult to measure otherwise than by means of self-report from the respondent or report from an observer (e.g., spouse, supervisor). Well-being and role engagement, however, could be assessed more objectively, for example via register-based sickness absence or hours spent in each life role. The third noteworthy limitation is that our data were female-dominated (86\%), raising the question of whether the findings would hold among male-dominated or more gender-neutral samples. Such samples need to be studied in future. Related to this are the facts that we studied only health care and service occupations and that the data were not nationally representative. The fourth limitation is that some coping groups (e.g., the 'highest' and 'passive' coper groups) were small, rendering statistical analysis difficult. For example, we had to reject the 'highest' coper group from the well-being analyses because there were too few cases. However, we want to emphasize that all seven coping groups differed from each other statistically (see Table 2 for fit indices of profile solutions).

The final limitation is psychometrical: the reliabilities of the coping strategy scales were not very good, although acceptable (alphas >.60). On the other hand, we relied on measurement error-free constructs because we used the latent factor scores of the coping scales. Lower reliabilities also reflect the fact that coping is difficult to assess via pre-defined scales [2, $3]$, and hence more conceptual and psychometrical development are needed.
Our findings indicate that employees should be trained to use active coping strategies (e.g., situation changing, accommodation). This should be kept in mind when planning and implementing stress interventions targeted at the working population. Successful coping is characterized in general terms as an individual's broad variety of available coping strategies serving different functions. In general, it has been recognized that successful coping means a good balance between different coping strategies and flexibility in the choice of coping action [1, 2, 4].

Overall, our results point to the conclusion that it is essential to understand and investigate coping as a many-sided construct [5, 8-10]. The most traditional approach, classifying coping into two or three main categories, is too narrow to enable us to properly understand the real nature of coping $[5,6]$ or how people cope in real life settings [7]. People seem to use different coping strategies simultaneously and to unravel this, a special methodological approach is needed, that is, a person-oriented rather than a variable-oriented view [9-11]. This study shows that, by exploring what sorts of combinations of coping strategies individuals are using, researchers might find fresh perspectives on generic coping strategies, which after all have been studied for decades.

Finally, a person-oriented analysis of coping strategies may also reveal whether certain coping strategies are used to compensate some other strategies. For instance, avoidance coping might be used if other, more adaptive, strategies are not available or have been unsuccessful, and thus one important aspect is an individual's coping flexibility. A sequencing process of coping strategies, i.e., how coping strategies change during a stress process within and between individuals, would also need more attention in subsequent person-oriented studies. Naturally, this kind of research requires longitudinal data. Answering these questions may also unravel why and how different coping profiles emerge and why

Appendix 1: $\quad$ Means of Normalized Factor Scores for Coping Profiles

\begin{tabular}{|ccccccccc|}
\hline Variable & $\begin{array}{c}\text { Within } \\
\text { group SD }\end{array}$ & $\begin{array}{c}\text { I } \\
(\mathbf{n}=\mathbf{1 2 5 1})\end{array}$ & $\begin{array}{c}\text { II } \\
(\mathbf{n}=\mathbf{3 5 1})\end{array}$ & $\begin{array}{c}\text { III } \\
(\mathbf{n}=\mathbf{3 4})\end{array}$ & $\begin{array}{c}\text { IV } \\
(\mathbf{n}=\mathbf{3 0 0})\end{array}$ & $\begin{array}{c}\text { V VI } \\
(\mathbf{n}=\mathbf{1 8 2})\end{array}$ & $\begin{array}{c}\text { VII } \\
(\mathbf{n}=\mathbf{4 0 6})\end{array}$ \\
$\mathbf{( n = 1 3 )}$
\end{tabular}

Note. Coping profiles: I = moderate copers, II = low copers, III = passive copers, IV = blurred copers, $\mathrm{V}=$ active copers, $\mathrm{VI}=$ high copers, $\mathrm{VII}=$ the highest copers. 
certain coping strategies co-occur more likely than the others.

\section{ACKNOWLEDGEMENTS}

This study was supported by the Finnish Work Environment Fund (Grant No. 106046) and the Academy of Finland (Grant No. 125422).

\section{REFERENCES}

[1] Pearlin $L$ and Schooler C. The structure of coping. J Health Soc Behav 1978; 19: 2-21. http://dx.doi.org/10.2307/2136319

[2] Lazarus RS. Stress and emotion: A new synthesis. Springer; 2006.

[3] Schwarzer R and Schwarzer C. A critical survey of coping instruments, in Handbook of coping. Theory, research and applications, Ed by Zeidner M and Endler NS Wiley-Blackwell 1996; pp. 107-132.

[4] Lazarus RS and Folkman S. Stress, appraisal, and coping. Springer 1984.

[5] Skinner EA, Edge K, Altman J and Sherwood H. Searching for the structure of coping: A review and critiques of category systems for classifying ways of coping. Psychol Bull 2003; 129: 216-269.

http://dx.doi.org/10.1037/0033-2909.129.2.216

[6] Carver CS, Scheier MF and Weintraub JK. Assessing coping strategies: A theoretically based approach. J Pers Soc Psychol 1989; 56: 267-283.

http://dx.doi.org/10.1037/0022-3514.56.2.267

[7] Compas BE, Connor-Smith JK, Saltzman H, Thomsen AH and Wadsworth ME. Coping with stress during childhood and adolescence: Problems, progress, and potential in theory and research. Psychol Bull 2001; 127: 87-127. http://dx.doi.org/10.1037/0033-2909.127.1.87

[8] Dewe P. A closer examination of the patterns when coping with work-related stress: Implications for measurement. J Occup Organ Psych 2003; 76: 517-524.

http://dx.doi.org/10.1348/096317903322591613

[9] Luyckx K, Vanhalst J, Seiffge-Krenke I and Weets I. A typology of coping with Type 1 diabetes in emerging adulthood: associations with demographic, psychological, and clinical parameters. J Behav Med 2010; 33: 228-238. http://dx.doi.org/10.1007/s10865-010-9249-9

[10] Aldridge AA and Roesch SC. Developing coping typologies of minority adolescents: A latent profile analysis. J Adolescence 2008; 31: 499-517.

http://dx.doi.org/10.1016/j.adolescence.2007.08.005

[11] Seiffge-Krenke I and Klessinger N. Long-term effects of avoidant coping on adolescents' depressive symptoms, J Youth Adolescence 2000; 29: 617-630. http://dx.doi.org/10.1023/A:1026440304695

[12] Magnusson D. The logic and implications of a personoriented approach, in Methods and models for studying the individual, Ed by Cairns RB, Bergman LR and Kagan J. Sage 1998; pp. 33-64.

[13] Bartholomew DJ and Knott M. Latent variable models and factor analysis. Arnold 1999.

[14] Walker LS, Baber KF, Garber J and Smith CA. A typology of pain coping strategies in pediatric patients with chronic abdominal pain. Pain 2008; 137: 266-275. http://dx.doi.org/10.1016/j.pain.2007.08.038

[15] Folkman S and Moskowitz JT. Coping: pitfalls and promises. Annu Rev Psychol 2004; 55: 745-774. http://dx.doi.org/10.1146/annurev.psych.55.090902.141456
Penley JA, Tomaka $\mathrm{J}$ and Wiebe JS. The association of coping to physical and psychological health outcomes: A meta-analytic review. J Behav Med 2002; 25: 551-603. http://dx.doi.org/10.1023/A:1020641400589

[17] Edwards JR. A cybernetic theory of stress, coping, and wellbeing in organizations. Acad Manage Rev 1992; 17: 238274.

http://dx.doi.org/10.2307/258772

[18] Edwards JR. Cybernetic theory of stress, coping, and wellbeing, in Theories of organizational stress, Ed by Cooper CL. Oxford University Press 1998; pp. 122-152.

[19] Edwards JR, Caplan RD and Harrison RV. Personenvironment fit theory: Conceptual foundations, empirical evidence and directions for future research, In Theories of organizational stress, Ed by Cooper CL. Oxford University Press 1998; pp. 28-67.

[20] Edwards JR and Baglioni, AJ Jr. The measurement of coping with stress: Construct validity of the ways of coping checklist \& the cybernetic coping scale. Work Stress 1993; 7: 17-31. http://dx.doi.org/10.1080/02678379308257047

[21] Aldwin CM and Revenson TA. Does coping help? A reexamination of the relation between coping and mental health. J Pers Soc Psychol 1987; 53: 337-348. http://dx.doi.org/10.1037/0022-3514.53.2.337

[22] Kahn WA. Psychological conditions of personal engagement and disengagement at work. Acad Manage J 1990; 33: 692724.

http://dx.doi.org/10.2307/256287

[23] Rothbard NP. Enriching or Depleting? The dynamics of engagement in work and family roles. Admin Sci Quart 2001; 46: $655-684$.

http://dx.doi.org/10.2307/3094827

[24] Baruch $Y$ and Holtom BC. Survey response rate levels and trends in organizational research. Hum Relat 2008; 61: 11391160.

http://dx.doi.org/10.1177/0018726708094863

[25] Brough $P$, O'Driscoll $M$ and Kalliath, T. Evaluating the criterion validity of the Cybernetic Coping Scale: Crosslagged predictions of psychological strain, job and family satisfaction. Work Stress 2005; 19: 276-292. http://dx.doi.org/10.1080/02678370500287507

[26] Guppy A, Edwards JA, Brough P, Sale C, Peters-Bean K and Short E. The Psychometric properties of the short version of the cybernetic coping scale. J Occup Organ Psych 2004; 77: 39-62. http://dx.doi.org/10.1348/096317904322915900

[27] Elo A-L, Leppänen A, Lindström K and Roponen T. The OSQ. How to use the Occupational. Stress Questionnaire. Helsinki: Finnish institute of occupational health 1990.

[28] Schumm WR, Paff-Bergen LA, Hatch RC, Obiorah FC, Copeland JM, Meens LD, Bugaighis MA. Kansas Marital Satisfaction Scale. J Marriage Fam 1986; 48: 381-387. http://dx.doi.org/10.2307/352405

[29] James D, Schumm W, Kennedy K, Grigsby C, Schectman K and Nichols C. Characteristics of the Kansas Parental Satisfaction Scale among two samples of married parents. Psychol Rep 1985; 57: 163-169. http://dx.doi.org/10.2466/pr0.1985.57.1.163

[30] Schaufeli WB, Salanova M, Gonzalez-Romá V and Bakker $A B$. The measurement of engagement and burnout: $A$ confirmative analytic approach. J Happ Stud 2002; 3: 71-92. http://dx.doi.org/10.1023/A:1015630930326

[31] Schaufeli WB, Bakker $A B$, and Salanova $M$. The measurement of work engagement with a short questionnaire. A cross-national study. Educ Psychol Meas 2006; 66: 706-716.

http://dx.doi.org/10.1177/0013164405282471 
[32] Greenhaus JH and Powell GN. When work and family are allies: A theory of work-family enrichment. Acad Manage Rev 2006; 31: 72-92.

http://dx.doi.org/10.5465/AMR.2006.19379625

[33] Carlson DS, Kacmar KM, Wayne JH and Grzywascz JG. Measuring the positive side of the work-family interface. Developing and validation of a work-family enrichment scale. J Vocat Behav 2006; 68: 131-164. http://dx.doi.org/10.1016/j.jvb.2005.02.002

[34] Shirom A. Feeling vigorous at work? The construct of vigor and the study of positive affect in organizations, In Research in organizational stress and well-being, Ed by Ganster D and Perrewe PL. JAI Press 2003; pp. 135-165.

[35] Boyar SL, Carr JC, Mosley DC and Carson CM. The development and validation of scores on perceived Work and Family Demand Scales. Educ Psychol Meas 2007; 67: 100115. http://dx.doi.org/10.1177/0013164406288173
[36] Elo A-L, Dallner $M$ and Gamberale $F$ et al., QPSNordic Manual (in Finnish). Helsinki: Finnish Institute of Occupational Health 2006.

[37] Muthén LK and Muthén BO (1998-2009). Mplus user's guide (6th edition). Los Angeles, CA: Muthén \& Muthén 1998-2009.

[38] Nagin DS. Group-based modelling of development. Harward University Press 2005.

[39] Carver CS and Connor-Smith J. Personality and coping Annu Rev Psychol 2010; 61: 679-704. http://dx.doi.org/10.1146/annurev.psych.093008.100352

[40] Ben-Zur H. Coping styles and affect. Int J Stress Manage 2009; 16: 87-101. http://dx.doi.org/10.1037/a0015731

Received on 14-03-2014

http://dx.doi.org/10.6000/1927-5129.2014.10.27

(C) 2014 Mauno et al.; Licensee Lifescience Global.

This is an open access article licensed under the terms of the Creative Commons Attribution Non-Commercial License (http://creativecommons.org/licenses/by-nc/3.0/) which permits unrestricted, non-commercial use, distribution and reproduction in any medium, provided the work is properly cited. 